\title{
TEORI ATAU KONSEP ALGORITMA PEMROGRAMAN
}

\author{
DISUSUN OLEH : PERIYANTI PURNAMASARI RAMBE \\ PMM4/SEM 3 \\ Jurusan Pendidikan Matematika \\ Fakultas Ilmu Tarbiah Dan Keguruan \\ Universitas Islam Negeri Sumatera utara (UINSU)
}

2021

\begin{abstract}
ABSTRAK
Alogaritma pemograman merupakan urutan logis pengambilan suatu keputusan untuk memecahkan suatu masalah.kata-kata yang harus logis dalam memecahkan masalah yaitu langkah-langkah yang tidak benar akan membarikan hasil yang salah.algoritma berasal dari kata algorism dan ritmis yang pertamakali diungkapkan oleh Abu Ja'far Muhammad Ibnu dalam bukunya.dalam perograman algoritma berarti suatu metode yang secara khusus yang tepat terdiri dari serangkaian langkah-langkah dan stratuktur yang ditulis secara sistematis yang dikerjakan untuk menyelesaikan masalah dengan bantuan computer.Pemrokraman merupakan kumpulan intruksi-intruksi tersendiri yang biasa nya disebut dengan source code yang dibuat oleh pembuat program itu sendiri.ahli dari sejarah matematika menemukan bahwa asal kata algoritma yang beral dari nama penulis buku itu sendiri.
\end{abstract}

\begin{abstract}
Programming algorithms are the sequence of making a decision to solve a problem. The words that must be logical in solving the problem are steps that will not actually give wrong results. The algorithm, which comes from the words algorithm and rhythmic, was first introduced by $\mathrm{Abu} \mathrm{Ja}$ far Muhammad Ibnu in his book. In programming algorithms means a method that is specifically precise consisting of steps and structures written systematically which are done to solve problems with the help of computers. Programming is a collection of separate instructions which are usually referred to as sources. code created by the programmer himself. Experts from the history of mathematics found that the origin of the word algorithm came from the name of the author of the book itself.
\end{abstract}

Kata kunci ; Mengetahui teori dan konsep algoritma perograman 


\section{PENDAHULUAN}

Algoritma merupakan urutan logispengambilan keputusan untuk memecahkan sebuah masalah matematika.kata logis itu merupakan suatu langkah-langkah yang nilai nya harus logis kebenarannya harus logis dan dapat ditentukan nilai nya itu benar atau salah.Suatu langkah-langkah yang tidak benar dapat memberikan suatu yang salah.programan adalah suatu kumpulan intruksi-intruksi tersendiri yang bisa disebut dengan soure code yang dibuat oleh programan.

Algoritma adalah urutan dari langkah-langkah logis penyelesaian masalah yang disusun secara sistematis. Kata logis yang berasal dari kata kunci dari sebuah algoritma. Langkah langkah tersebut harus dapat ditentukan.benar atau slah langkah-langkah didalam algoritma tersebut harus dapat ditentukan. Algoritma juga merupakan suatu jantung ilmu computer atau informatika. Banyak cabang ilmu Komputer yang diacu dalam teknologi dalam terminology algoritma. Namun jangan beranggapan algoritma selalu identic dengan ilmu komputer saja. Komputer hanyalah salah satu dari pemproses agar dilaksanakan oleh computer,algoritma harus ditulis dalam notasi Bahasa perograman sehingga dinamakan program. Program adalah perwujutan atau implementasi teknis algoritma yang ditululis dalam Bahasa programan tertentu sehingga dapat dilangsanakan oleh komputer.

Algoritma adalah urutan logis dari pengambilan keputusan untuk pemecahan masalah. Algoritma diperlukan untuk menginstruksikan komputer untuk mengambil langkah-langkah tertentu dalam memecahkan masalah.

Alasan mengapa algoritma banyak digunakan dalam pemrograman:

a) Pembuatan atau penulisan algoritma tidak bergantung pada bahasa pemrograman apa pun.

b) Notasi algoritma dapat diterjemahkan ke dalam berbagai bahasa pemrograman.

c) Apapun bahasa pemrogramannya, outputnya akan sama karena algoritmanya sama.

1.2.1 Pengertian Algoritma menurut para ahli :

sebuah. Seymour Lipschutz, Ph.D. dan Marc Lipson, Ph.D.

Algoritme adalah daftar instruksi langkah demi langkah yang terbatas

didefinisikan dengan jelas yang digunakan untuk masalah tertentu.

B. David bolton

Mengatakan bahwa Algoritma itu adalah deskripsi dari sebuah prosedur yang berakhir dengans sebuah hasil.

C. Andrey Andreyevich Markov

Mengatakan bahwa Algoritma adalah hal yang begitu umum untuk dipahami sebagai keputusan yang tepat untuk mendefenisikan proses komputasi yang mengarah dari data awal ke data hasil diinginkan untuk dikalahkan. 


\section{Batu dan Knuth}

Algoritma adalah seperangkat aturan yang secara tepat menentukan urutan operasi sedemikian rupa sehingga setiap aturan yang efektif, jelas sampai tingkat tertentu sehingga urutan berakhir dalam waktu yang terbatas.

e. amikom yogyakarta

Pengertian algoritma adalah suatu bentuk instruksi berupa metode atau metode yang akan membantu Anda dalam menyelesaikan program dengan cara yang lebih sistematis.

F. minsky

Algoritme adalah seperangkat aturan yang memberi tahu kita dari waktu ke waktu tepatnya bagaimana kita harus bertindak

Kata "algoritma" dan kata "program" seringkali dipertukarkan dalam penggunaannya misalnya ada orang berkata seperti ini: bagaimana algoritma yang ditulis dalam bahasa Teks algoritma berisi deskripsi langkah-langkah ditulis dalam notasi apa pum, asalkan mudah dibaca dan dimegarti. Tidak ada notasi yang baku dalam penulisan tek algoritma sebagaimana pada notasi Bahasa pemrograman. Tiap orang dapat membuat aturan penulisan dan notasi program. Program adalah implementasi algoritma dalam notasi bahas pemrograman ,agar notasi algoritama mudah di tranlasi kedalam notasi Bahasa pemrograman ,maka sebaiknya notasi algoritma tersebut berkoresponden dengan notasi pemrograman secara umum. Karena pelajaran algoritma menggunakan pradikma procedural,maka pada bagian data dan bagian intruksi dipisahkan tempatnya. Pada dasarnya teks algoritma selalu disusun oleh 3 bagian yaitu: 1. Bagian judul 2. Bagian deklarasi 3. Bagian deskripsi algoritma.

Ahli dalam sejarah matematika menemukan asla kata dari algoritma itu berasal dari nama penulis buku arab yang terkenal yaitu: Abu Ja'far Muhammad Ibnu Musa AlKhuwarizmi. AlKhuwarizmi dibaca orang barat menjadi Algorism. Al-Khuwarizmi menulis buku yang berjudul dari Kitab Al Jabar Wal-Muqabala yang merupakan artinya adalah "Kitab pemugaran dan pengurangan"(Buku restorasi dan pengurangan). Daru buku yang berjudul ini asal dari akar adalah"Aljabar" (Aljabar). Perubahan kata dari algoritma menjadi algoritma muncul karena kata algoritma sering dikacaukan dengan aritmatika,jadi sufiks usm berubah menjadi utm. Karena perhitungan dengan angka arab sudah menjadi hal yang lumrah, maka lambat laun kata algoritma penggambaran digunakan sebagai metode perhitungan (perhitungan) secara umum, sehingga kehilangan arti kata sedih. Dikatakan, yahoo bukanlah sesuatu yang asing bagi kita. Penemunya adalah seorang ahli matematikawan dari Uzbekistan bernama Abu Abdullah Muhammad Ibn Musa Al Khawarizmi (770-840). Dalam sastra barat ia lebih dikenal dengan sebutan Algorizm. panggilan yang kemudian digunakan untuk 
merujuk pada konsep algoritma yang dia menemukan. Dalam bahasa Indonesia kita kemudian menyebutnya sebagai yahoo.

Alogaritma adalah kunci dari bidang ilmu komputer, karena banyak yang berbeda dari dibawah dari sains karena computer yang lahir berdasarkan konsep dari suatu algoritma yang juga pada dasarnya merupakan dari kata kunci hidup kita sebagai mahlu tuhan.

\section{METODE PENELITIAN}

Metode yang digunakan adalah konsep pengelolaan dan analisis dari data statistic, efisiensi dalam algoritma pemrograman. Pada dasarnya algoritma merupakan deskripsi pelaksanan dari sebuah proses bahwa sebuah proses dikerjakan oleh pemroses menurut dari algoritma yang telah ditulis. Bahwa algoritma disusun oleh sederetan langkah intruksi yang logis, setiap langkah intruksi tersebut mengerjakan suatu tindakan atau aksi yang bila dilaksanakan yang sesuai dengan aksi yang dikerjakan oleh pemproses. Epek dari pengerjaan suatu aksi dapat diamati dengan membandingkan keadaan pada saat aksi belum dimulai

Dasar-dasar pembelajaran algoritma pemrograman

1. perbedaan antara algoritma dan program

Penting untuk mengetahui perbedaan antara algoritma dan program. Seperti yang telah disebutkan di atas, algoritma pemrograman adalah langkah sistematis dan terstruktur yang digunakan untuk menyusun sebuah program. Sedangkan programnya sendiri merupakan implementasi dari bahasa pemrograman dan algoritma pemrograman.

\section{Memahami konsep dasar algoritma pemrograman}

Perlu Anda ketahui, ada tiga jenis langkah yang bisa digunakan dalam sebuah algoritma. Apa masalahnya?

Seleksi (pilih tindakan) $=$ diterapkan dalam program yang tugas atau pernyataannya menggunakan sistem pemilihan kondisi;

Pengulangan tindakan $=$ digunakan dalam program yang tugas atau pernyataannya diulang; Urutan (tindakan berurutan) = digunakan oleh program yang tugas atau pernyataannya dilakukan secara berurutan, langkah demi langkah.

3. Cari tahu tentang istilah dasar algoritma 
Jika anda sudah memahami konsep dasar algoritme, ada baiknya anda juga mengetahui tentang istilah dasar algoritme. Sehingga Kisanak dapat dengan mudah merumuskan algoritma yang akan dibuat.

\section{Pelajari cara menyajikan algoritma pemrograma}

Ada dua bentuk untuk menyajikan algoritma pemrograman. Anda dapat mencoba menyajikan algoritma pemrograman dengan menggunakan gambar atau dengan menulis. Biasanya programmer menggunakan flowchart untuk menyajikan algoritma pemrograman dengan gambar dan menggunakan pseudocode untuk menyajikan algoritma pemrograman dengan tulisan.

\section{Cari teman untuk belajar bersama}

Anda dapat mempelajari algoritma pemrograman dengan mencari teman dan atau sekelompok programmer. Melalui grup ini, Anda akan dapat belajar banyak tentang algoritma pemrograman, selain itu, Anda dapat lebih mudah menemukan dan mempelajari di mana kesalahan ketika memprogram algoritma dari para ahli.

Struktur Penulisan Algoritma Setiap Algoritma akan selalu terdiri dari tiga bagian yaitu:

a) Judul (Header) Judul adalah bagian teks algoritma yang digunakan sebagai tempat mendefinisikan nama dengan menentukan apakah teks tersebut adalah program, prosedur, fungsi.

b) Kamus Kamus adalah bagian teks algoritma sebagai tempat untuk mendefinisikan :

- Nama type

- Nama konstanta

- Nama fariabel

- Nama fungsi

- Nama prosebur 


\section{HASIL DAN PEMBAHASAN}

Alogaritma adalah suatu system yang kerja komputer memiliki brainware, hardware, dan software. Tanpa salah satu dari ketiga system tersebua, computer tidak akan berguna dan kita akan lebih focus kepada softwarec komputer. Software itu terbangun dari suatu susunan ( program) dan syntax (cara penulisan/pembuatan program). Untuk menyusun suatu program atau system, diperlukannya suatu langkah-langkah yang sistematis dan lagis untuk mendapatkan masalah atau tujuan dalam suatu proses pembuatan software. Maka algoritma berperan dalam suatu penyusunan dari kata yang logis dan sistematis untuk memecahkan suatu masalah atau untuk mencapai tujuan tertentu. Dalam dunia komputer, algoritma sangat berperan penting dalam pembangunan suatu software. Dalam suatu dunia sehari-hari mungkin tanopa kita sadari bahwa algoritma itu sangat berbeda dengan logaritma. Logaritma merupakan operasi matematika yang merupakan kebalikan dari eksponen atau pemangkatan. Contoh $\operatorname{logaritma}$ seperti $\mathrm{bc}=\mathrm{a}$ ditulis sebagai blog $\mathrm{a}=\mathrm{c}$ (b disebut basis).

Ada 5 ciri-ciri yang penting yang harus dipenuhi dalam algoritma yaitu:

1. Algoritma harus berhenti setelah mengerjakan sejumlah langkah dalam program yang tidak berperan penting dan tidak pernah berhenti dalam program berisi algoritma yang.

2. Setiap langkah harus didepenisikan dengan langkah yang tepat dan bersekala.

3. Algoritma memiliki nol atau lebih kurang (input).

4. Algoritma memiliji nol atau lebih kurang (output)

5. Algoritma harus efektif.

\section{Notasi Algoritma}

- Notasi I : diagram liur (flowchart)

- Notasi II: pseudo-code

Contoh masalah : menghitung luas segiempat.

\section{Ciri-ciri algoritma :}
a. Ada input.
b. Ada proses.
c..Ada output.
d. Memiliki instruksi-instruksi yang jelas dan tidak ambigu. 


\section{Sifat algoritma :}

a. Tidak menggunakan simbol atau sintaks dari suatu bahasa pemrograman

b. Tidak tergantung pada suatu bahasa pemrograman

c. Notasi-notasinya dapat digunakan untuk seluruh bahasa manapu

\section{Pemrograman Prosedural}

- program dibedakan antara bagian data dengan bagian instruksi.

- Bagian instruksi terdiri atas runtutan (se-quence) instruksi yang dilaksanakan satu per satu secara berurutan oleh pemroses. Alur pelaksanaan instruksi dapat berubah karena adanya pencabangan kondisional.

- Data yang disimpan di dalam memori dimanipulasi oleh instruksi secara beruntun atau procedural.

Pada dasarnya,sebuah algoritma merupakan suatu deskripsi suatu proses bahwa suatu proses dikerjakan oleh suatu pemproses menurut algoritma yang sudah ditulis. Algoritma disusun oleh sederetan melalui langkah intruksi dan logis. Setiap langkah intruksi tersebut mengerjakan suatu proses tindakan.efek dari pengerjaan sejumlah operasi yang bersesuaian dengan aksi itu dikerjakan oleh pemproses.

Penulisan harus algoritma yang baik selalu disertai dengan pemberian komentar. Komentar merupakan suatu penjelasan mengenai suatu hal yang tertulis dalam suatu algoritma dan komentar bukanlah merupakan dari suatu bagian dan langkah-langkah penyelesaian dari suatu algoritma. Komentar ditulis di antara tanda baca kurung kurawal buka dan kurung kurawal tutup. Tulisannya seperti berikut ini adalah contoh kurung “ \{\} “. Pada bagian kepala algoritma, penjelasan algoritma merupakan suatu komentar. Contoh lainnya dapat Anda lihat dalam contoh bagian deklarasi di atas. Pemberian komentar bukanlah suatu keharusan, namun algoritma yang disertai dengan komentar-komentar yang tepat akan memudahkan setiap pembaca lainnya untuk mengerti apa itu algoritma yang dibuat. Dalam algoritma, ada beberapa hal yang harus diberi nama atau pengenal. Hal-hal tersebut meliputi sebagai beikut ini: nama algoritma, nama tetapan (konstanta), nama peubah (variabel), nama tipe, nama prosedur, dan nama fungsi. Pemberian nama harus mengikuti aturanaturan sebagai berikut:

1) Hanya boleh terdiri dari huruf, angka, atau garis bawah.

2) Tidak boleh dimulai dengan angka

3) Tidak membedakan huruf kapital maupun huruf kecil (non case-sensitive) 
4) Panjang tidak dibatasi

5) Harus unik, artinya tidak boleh ada nama pengenal yang sama untuk hal yang berbeda

6) Hendaknya mencerminkan kegunaannya Pemberian nama pengenal ini biasanya mengikuti salah satu dari 2 gaya berikut:

1. pemisah antar-kata menggunakan tanda garis bawah.

Contoh: Luas_Segitiga

2. pemisah antar-kata menggunakan huruf kapital

Contoh: LuasSegitiga Beberapa contoh penamaan yang valid maupun tidak valid:

- Nama_4_Pegawai $\{$ valid $\}$

-2_luas \{ salah, karena diawali angka\}

- ^LuasSegitiga $\left\{\right.$ salah, karena terdapat tanda $\left.{ }^{\wedge}\right\}$

- Luas_Segitiga_\&_Lingk $\{$ salah, karena terdapat tanda \& $\}$

- Hati2 \{valid\}

To : Keadaan sebelum aksi dikerjakan aksi

T1 : Keadaan setelah aksi

Sebagai contoh,dapat kita tinjau dari kembali algoritma yang menggambarkan perosos pertukaran larutan dari dua buah bejana A dan B. pada setiap pelaksanaan dapat kita amati keadaan awal dari keadaan akhir.

To : Bejana A berisi larutan barwarna merah,bejana B berisi larutan berwarna biru (bejana $\mathrm{C}$ masih kosong)

1. Tuangkan larutan dari bejana $\mathrm{A}$ ke dalam bejana $\mathrm{C}$

T1 :

Bejana A kosong, bejana $\mathrm{C}$ berisi larutan berwarna merah

To : Bejana A kosong, bejana B larutan berwarna biru

2. tuangkan larutan dari bejana B kedalam bejana A 
T1 : Bejana A berisi larutan berwarna biru bejana B kosong

To : Bejana B kosong, bejana $\mathrm{C}$ berisi larutan berwarna merah

3. tuangkan larutan dari bejana $\mathrm{C}$ kedalam bejana $\mathrm{B}$

T1: Bejana berisi larutan berwarna merah, bejana A sudah berisi larutan berwarna biru (bejana c kosong).

Algoritma Euclidean dapat dapat dipandang sebagai sebuah proses mencari pembagi Bersama terbesar dari dua buah bilangan bulat positif, $\mathrm{M}$ dan $\mathrm{N}$.

To : $m \geq 0, n \geq 0$, dan $m \geq n$

1. Jika $n=0$, maka m adalah jawabannya; stop, tetapi jika $n \neq 0$, lanjutkan ke langkah 2 .

$\mathrm{T} 1: \mathrm{n}=0$ (m adalah jawabannya) atau $\mathrm{n} \neq 0$

To : $\mathrm{n} \neq 0$

2. bagian $\mathrm{m}$ dengan $\mathrm{n}$ dan misalkan $\mathrm{r}$ adalah sisanya

$\mathrm{T} 1$ : $\mathrm{r}$ adalah sisa hasil bagi, $0 \leq \mathrm{r}<\mathrm{n}$

T0 : r adalah sisa hasil bagi, $0 \leq \mathrm{r}<\mathrm{n}$

3. ganti nilai $\mathrm{m}$ dengan nilai n,dan nilai $\mathrm{n}$ dengan nilai r,ulang kembali kelangkah 1 .

$\mathrm{T} 1: \mathrm{m}=\mathrm{n}$ dan $\mathrm{n}=\mathrm{r}$

Pada kedua algoritma diatas diperhatikan bahwa memperlihatkan kenyataan bahwa keadaan akhir sebuah akhir dapat menjadi keadan awal untuk aksi selanjutnya. Hal ini benar, karena setiap setiap langkah dikerjakan secara beruntun karena sesuai dengan urutannya didalam alogaritma. Algoritma juga dapat dipandang sebagai sebuah aksi benar yang disusun oleh beberapa aksi yang lebih sederhana. Keadaan awal dari aksi pertama merupakan keadaan akhir algoritma. Jika to adalah keadaan sebelum algoritma dikerjakan dan T1 adalah keadaan sesudah algoritma dikerjakan,maka pada lagoritma pertukarkan isi dua buah bejana:

To : Bejana berisi larutan berwarna merah,bejana B berisi larutan berwarna biru Algoritma TUKAR ISI BEJANA

T1 : Bejana B berisi larutan berwarna merah, bejana A sudah berisi larutan berwarna 


\section{Biru}

Dan pada algoritma Euclidean :

To : $\mathrm{m} \geq 0, \mathrm{n} \geq \mathrm{o}$, dan $\mathrm{m} \geq \mathrm{n}$

Algoritma Euclidean

$\mathrm{T} 1: \mathrm{n}=0$, sehingga $\mathrm{m}$ adalah jawabannya

Algoritma Euclidean berhenti bila hasil bagi m dengan $n$ menghasilkan sisa nol. Jadi, keadaan akhir adalah $\mathrm{n}=0$ sehingga $\mathrm{m}$ adalah jawabannya. Keadaan awal dan keadaan akhir algoritma dapat dijadikan acuan bagi pemrograman dalam merancang sebuah algoritma. Keadaan akhir ini mencerminkan hasil yang diinginkan dari sebuah keadaan awal.

Tahap-tahap penyusunan algoritma sering kali dimulai dari langkah yang diglobal lebih dahulu. Langkah global ini diperhalus sampai kelangkah yang lebih rinci. Pendekatan desain algoritma seperti ini dinamakan sebuah penghalusan sebuah langkah atau perancangan sebuah puncak. Cara pendekatan ini sangat bermanfaat dalam pembuatan algoritma untuk masalah yang paling rumit atau komplek. Tiap langkah diuraikan lagi menjadi beberapa langkah yang lebih sederhana.penghalusan langh tersebut sudah cukup rinci dan tepat untuk dilangsanakan oleh proses.

Struktur dasar algoritma

Algoritma berikan langkah-langkah penyelesaian suatu masalah. Langkah-langkah tesebut dapat berupa runtunan aksi. Pemilihan aksi, dan pengulangan aksi. Ketiga jenis langkah tersebut membentuk konstruksi suatu algoritma. Jadi, sebuah algoritma dapat dibangun dari tiga buah struktur dasar,yaitu :

\section{Runtunan}

Sebuah runtunan terdiri dari satu atau lebih intruksi. Setiap intruksi dikerjakan secara berurutan sesuai dengan urutan penulis nya, yakni sebuah intruksi dilaksanakan setelah intruksi lainnya selesai dilaksanakan.

\section{Pemilihan}

Sebuah intruksi dikerjakan jika kondisi tertentu dipenuhi. Jika kondisi dipenuhi tinjau kembali algoritma pengurutan dari data. Pencarian data kecil dilakukan dengan membandingkan bandingan dari sebuah data.

3. pengulangan 
Salah satu dari kelebihan sebuah computer adalah kemampuannya untuk mengerjakan mengerjakan pekerjaan yang sama dengan berulang-ulang tanpa mengenal Lelah. Ini berbeda dengan manusia yang cepat Lelah bila mengerjakan pekerjaan pekerjaan yang sma bila berulang-ulang.

Teks algoritma berisi deskripsi langkah-langkah penyelesaian masalah. Deskrifsi tersebut dapat ditulis dengan notasi apa pun. Tiap orang dapat membuat aturan penulisan dan notasi algoritma sendiri. Hal ini dapat dimengerti karena teks algoritma tidak sama dengan teks program.

\section{KESIMPULAN}

Algoritma merupakan urutan logispengambilan keputusan untuk memecahkan sebuah masalah matematika.kata logis itu merupakan suatu langkah-langkah yang nilai nya harus logis kebenarannya harus logis dan dapat ditentukan nilai nya itu benar atau salah.Suatu langkah-langkah yang tidak benar dapat memberikan suatu yang salah.programan adalah suatu kumpulan intruksi-intruksi tersendiri yang bisa disebut dengan soure code yang dibuat oleh programan.

Algoritma adalah urutan dari langkah-langkah logis penyelesaian masalah yang disusun secara sistematis. Kata logis yang berasal dari kata kunci dari sebuah algoritma. Langkah langkah tersebut harus dapat ditentukan.benar atau slah langkah-langkah didalam algoritma tersebut harus dapat ditentukan. Algoritma juga merupakan suatu jantung ilmu computer atau informatika. Banyak cabang ilmu Komputer yang diacu dalam teknologi dalam terminology algoritma. Namun jangan beranggapan algoritma selalu identic dengan ilmu komputer saja. Komputer hanyalah salah satu dari pemproses agar dilaksanakan oleh computer,algoritma harus ditulis dalam notasi Bahasa perograman sehingga dinamakan program. Program adalah perwujutan atau implementasi teknis algoritma yang ditululis dalam Bahasa programan tertentu sehingga dapat dilangsanakan oleh computer.

Seymour Lipschutz, Ph.D. dan Marc Lipson, Ph.D.

Algoritme adalah daftar instruksi langkah demi langkah yang terbatas didefinisikan dengan jelas yang digunakan untuk masalah tertentu.

B. David Bolton

Algoritma adalah deskripsi prosedur yang berakhir dengan hasil.

C. Andrey Andreyevich Markov 
Algoritma adalah hal yang umum untuk dipahami sebagai keputusan yang tepat untuk mendefinisikan proses komputasi yang mengarah dari data awal ke hasil akhir diinginkan.

D. Batu dan Knuth

Algoritma adalah seperangkat aturan yang secara tepat menentukan urutan operasi sedemikian rupa sehingga setiap aturan yang efektif, jelas sampai tingkat tertentu sehingga urutan berakhir dalam waktu yang terbatas.

e. amikom yogyakarta

Pengertian algoritma adalah suatu bentuk instruksi berupa metode atau metode yang akan membantu Anda dalam menyelesaikan program dengan cara yang lebih sistematis.

F. minsky

Algoritme adalah seperangkat aturan yang memberi tahu kita dari waktu ke waktu tepatnya bagaimana kita harus bertindak

Pada dasarnya,sebuah algoritma merupakan suatu deskripsi suatu proses bahwa suatu proses dikerjakan oleh suatu pemproses menurut algoritma yang sudah ditulis. Algoritma disusun oleh sederetan melalui langkah intruksi dan logis. Setiap langkah intruksi tersebut mengerjakan suatu proses tindakan.efek dari pengerjaan sejumlah operasi yang bersesuaian dengan aksi itu dikerjakan oleh pemproses. 


\section{DAFTAR PUSTAKA}

Liem, Inggriani, Diktat kuliah Algoritma dan Pemograman Prosedural Jurusan Teknik Informatika ITB, 1996

Kernighan, Brian W dan Richie, Dennis M, The Ansi C Programming Laguage, Prentice Hall, 1988

Parson, Thomas W. Introduction to algoritma in Pascal, Jhons Wiley and sons, inc, 1995

Brassard G. and Bratley P.“Fundamentals of Algorithmics”. Prentice Hall, New Jersey, 1996.

Munir, Rinaldi. “Algoritma Divide and Conquer”. Institut Teknologi Bandung. Bandung 2004.

Bibi, S. (2015). Efektivitas Penerapan Blended Learning Mata Kuliah Algoritma Dan Pemrograman. Jurnal Pendidikan Informatika Dan Sains, 4(2), 274-286.

Bibi, S., \& Jati, H. (2015). Efektivitas Model Blended Learning Terhadap Kuliah Algoritma Dan Pemrograman. Jurnal Pendidikan Vokasi, 5(1), 74-87.

Dakhi, O., Jama, J., Irfan, D., Ambiyar, \& Ishak. (2020). Blended Learning: A 21st Century Learning Model At College. International Journal Of Multi Science, 1(7), 1723.

Sedgewick, Robert. “Algorithms”.Addison Wesley Publishing Company. 1983.

Ardiansyah, ivan. 2013. Eksplorasi pola komunikasi dalam diskusi menggunakan moddle pada perkuliahan simulasi pembelajaran kimia, universitas pendidikan indonesia, bandung-indonesia. 